\title{
Effect of bixalomer on coronary artery calcification in hemodialysis patients with hyperphosphatemia: a multi-center, randomized controlled trial
}

\author{
Takashi Akiba ${ }^{1,6^{*}}$, Keitaro Yokoyama², Hiroki Hase ${ }^{3}$, Masahide Mizobuchi ${ }^{4}$, Ryoichi Ando ${ }^{5}$, Shuji Sakai ${ }^{5}$,
} Kenji Fukushima ${ }^{5}$ and Tadao Akizawa ${ }^{4}$

\begin{abstract}
Background: Calcium carbonate is a first-line therapy for hyperphosphatemia in hemodialysis patients but is associated with progressive coronary and aortic calcification. Sevelamer compounds are alternatives to calciumcontaining phosphate binders as they contain lower calcium levels. The sevelamer compound, bixalomer, is a calcium-free insoluble polymer that has been shown to be effective and safe in comparison with calcium carbonate. We therefore compared the effect of bixalomer vs calcium carbonate on coronary artery calcification in hemodialysis patients with hyperphosphatemia.
\end{abstract}

Methods: In this open-label, randomized phase IV trial across 23 sites throughout Japan, 85 patients with chronic kidney disease were randomized to bixalomer $(n=44)$ or calcium carbonate $(n=41)$ therapy and monitored for 12 months. Bixalomer was administered at a dosage of $1500 \mathrm{mg} /$ day $(500 \mathrm{mg}$ three times a day) and calcium carbonate was administered at a dosage of $3000 \mathrm{mg} /$ day (1000 mg three times a day). The primary outcome was the change in coronary artery calcium over time measured using computed tomography. Levels of serum phosphorus, calcium, intact parathyroid hormone, and the occurrence of adverse events were also reported over the course of the study.

Results: The mean ( \pm standard deviation) changes in coronary artery calcium scores from baseline to 12 months were significantly higher in the calcium carbonate vs bixalomer group ( $268.6 \pm 320.1$ vs $126.7 \pm 154.8$, respectively; between-group difference $p=0.029$ ). At 12 months in the bixalomer group, serum phosphorus and intact parathyroid hormone levels were significantly higher; serum calcium was significantly lower $(p<0.05)$. The most frequent adverse events were shunt stenosis in the bixalomer group, and shunt stenosis and common cold in the calcium carbonate group. There were no significant between-group differences in adverse drug reaction incidences.

Conclusions: The safety profile of bixalomer was comparable to that of calcium carbonate. Bixalomer further reduced coronary artery calcification, compared with calcium carbonate, in hemodialysis patients with hyperphosphatemia.

Trial registration: UMIN/R000015330 Registered 13 February 2014

Keywords: Bixalomer, Coronary calcification, Hemodialysis, Randomized clinical trial

\footnotetext{
* Correspondence: takashi.akiba@tokyonext.jp

${ }^{1}$ Tokyo Women's Medical University Hospital, Tokyo, Japan

${ }^{6}$ Present address: Tokyo Next Clinic, 2-22-1 Nishinippori Arakawaku, Tokyo

1160013, Japan

Full list of author information is available at the end of the article
}

(c) The Author(s). 2019 Open Access This article is distributed under the terms of the Creative Commons Attribution 4.0 International License (http://creativecommons.org/licenses/by/4.0/), which permits unrestricted use, distribution, and reproduction in any medium, provided you give appropriate credit to the original author(s) and the source, provide a link to the Creative Commons license, and indicate if changes were made. The Creative Commons Public Domain Dedication waiver (http://creativecommons.org/publicdomain/zero/1.0/) applies to the data made available in this article, unless otherwise stated. 


\section{Background}

Mineral and bone disorder (MBD) is common in patients with renal failure who are on hemodialysis [1]. Abnormalities in phosphorus, calcium, parathyroid hormone (PTH), and alkaline phosphatase are frequently seen in these patients. These abnormalities not only affect the bones and parathyroid glands but can also lead to vascular calcification, which can contribute to cardiovascular disease and cardiovascular death [2]. Serum concentrations of phosphorus, calcium, calcium-phosphorus product, and PTH are significant and independent risk factors of vascular calcification and are associated with all-cause mortality and cardiovascular mortality in these patients [3].

Hyperphosphatemia is associated with vascular, skeletal, and renal abnormalities. The control of serum phosphorus concentrations in chronic kidney disease (CKD) is important to limit bone lesions or their progression, as well as to limit the progression of vessel lesions [4].

There are global guidelines that provide treatment targets and emphasize the importance of the control of blood phosphorus concentrations [5-7]. Kidney Disease: Improving Global Outcomes (KDIGO) has published the KDIGO clinical practice guideline for the diagnosis, evaluation, prevention, and treatment of CKD-MBD. These guidelines explain that tailored treatment of CKD-MBD lowers phosphorus and maintains calcium levels [7].

Advances in diagnostic modalities have revealed a high probability of circulatory complications and demonstrate coronary artery calcification in chronic hemodialysis patients [8]. Several factors have been associated with the presence and progression of calcified coronary artery lesions. These include hyperparathyroidism, calcium-containing dialysis fluid, and calcium carbonate orally administered as a phosphorus-lowering drug.

Sevelamer carbonate and sevelamer hydrochloride are alternatives to calcium-containing phosphate binders as they contain lower levels of calcium [9]. Compared with calcium-based phosphate binders, sevelamer has been reported to cause fewer abnormalities of calcium and PTH, and less progressive coronary and aortic calcification in both chronic hemodialysis patients [10] and patients new to hemodialysis [11]. Similar results have been reported in a randomized study in Japan $(n=183)$. When compared with those receiving calcium carbonate $(n=92)$, patients on maintenance hemodialysis receiving sevelamer $(n=91)$ showed a significantly smaller increase in the coronary artery calcification score [12].

Despite this evidence, calcium carbonate remains the first-line drug for hyperphosphatemia in hemodialysis patients who continue to be at risk of increased coronary artery calcification [8]. Moreover, arterial calcification is reported to increase with the duration of hemodialysis and the dose of calcium-based phosphate binders [13].
Bixalomer is a calcium-free insoluble polymer for the treatment of hyperphosphatemia in patients on hemodialysis. The non-inferiority of the phosphorus-lowering effect of bixalomer compared with sevelamer hydrochloride has been confirmed. In a multi-center, open-label, randomized non-inferiority study, the baseline-adjusted mean serum phosphorus level at 12 weeks was $5.87 \mathrm{mg} / \mathrm{dL}$ in the bixalomer group and $5.55 \mathrm{mg} / \mathrm{dL}$ in the sevelamer group (difference of $0.31 \mathrm{mg} / \mathrm{dL} ; 95 \%$ confidence interval [CI] -0.13 , 0.76). Unlike sevelamer, bixalomer does not affect the concentration of bicarbonate ions, which is an indicator of metabolic acidosis [14]. Another advantage of bixalomer is that it lacks calcium, iron, and other metal ions and is less likely to cause digestive disorders such as constipation [15].

Bixalomer is expected to provide benefits beyond the treatment of hyperphosphatemia in a wide range of patients who are under maintenance hemodialysis because it has been found to have a lipid-lowering effect $[14,16]$. Although clinical experience with bixalomer in patients on hemodialysis who present hyperphosphatemia has suggested the usefulness of this drug $[15,17]$, it remains to be determined if bixalomer is more effective than calcium carbonate in limiting the progression of vascular calcification in these patients. The current study aimed to compare the effect of bixalomer vs calcium carbonate on coronary artery calcification in hemodialysis patients with hyperphosphatemia.

\section{Patients and methods}

\section{Trial design}

This was a multi-center, open-label, randomized phase IV trial in CKD patients who were undergoing blood purification therapy. The study was conducted at 23 sites across Japan, including the Department of Blood Purification, Kidney Center, Tokyo Women's Medical University Hospital from April 2013 to March 2016 (patients were registered by March 2015).

\section{Participants}

CKD patients aged $\geq 20$ years receiving hyperphosphatemia treatment with blood purification therapy for $>3$ months who provided written informed consent were recruited. Patients with serum phosphorus concentration $>8.0 \mathrm{mg} / \mathrm{dL}$, ileus, serious and chronic constipation or diarrhea, peptic ulcer/history of abdominal surgery, hypothyroidism, advanced heart disease, (New York Heart Association class III or higher), and impaired hepatic function were excluded from the study. Patients who were hospitalized for treatment of cerebrovascular or heart disease in the previous month, those who underwent thoracic surgery (including stent therapy and implantation of a pacemaker), those with liver function impairment or serious liver disease, those ineligible to undergo computed tomography (CT) scanning, and pregnant and lactating women were also excluded. 


\section{Interventions}

Eligible patients were randomized (1:1) to receive bixalomer (Kiklin ${ }^{\oplus}$ Astellas Pharma Inc., Tokyo, Japan) or calcium carbonate (Caltan-OD ${ }^{\circ}$, Mylan N.V., Pennsylvania, USA) for a period of 12 months. After screening, there was no washout period and the two groups were stratified by lanthanum carbonate usage (yes/no) and presence of coexistent diabetes (yes/no).

Bixalomer was administered at a dose of $1500 \mathrm{mg} /$ day (500 mg three times a day before meals) after discontinuing calcium carbonate and other medication for hyperphosphatemia. The maximum dose was $7500 \mathrm{mg} /$ day, adjusted depending on serum phosphorus levels to maintain a target level of $3.5-6.0 \mathrm{mg} / \mathrm{dL}$ following the Clinical Practice Guidelines for Metabolism Disorder of Bone and Mineral in Chronic Kidney Disease (Japanese Society for Dialysis Therapy) [18]. Calcium carbonate was administered at a dose of $3000 \mathrm{mg} /$ day $(1000 \mathrm{mg}$ three times a day) after discontinuing hyperphosphatemia medications. The dose was adjusted as needed to maintain a serum phosphorus target level of 3.5-6.0 mg/dL and a serum calcium target level of $8.4-10.0 \mathrm{mg} / \mathrm{dL}$ [18]. For both groups, lanthanum carbonate could be administered to adjust the serum phosphorus level if it was $>6.0 \mathrm{mg} / \mathrm{dL}$ even at the maximum dose of bixalomer $(7500 \mathrm{mg} /$ day $)$ or calcium carbonate $(3000 \mathrm{mg} /$ day). Lanthanum carbonate was administered at a starting dose of $750 \mathrm{mg} /$ day, up to a maximum of $2250 \mathrm{mg} /$ day according to the package insert (http://database.japic.or.jp/pdf/newPINS/00056030.pdf).

If it proved difficult to maintain the serum phosphorus concentration and the use of prohibited medications was required after taking all the available actions above, the patient was withdrawn. The patient was also withdrawn if discontinuation of the randomized study drug and a switch to other hyperphosphatemia medication were required.

Adjustment of serum calcium or serum intact $\mathrm{PTH}$ levels followed the Clinical Practice Guidelines for $\mathrm{Me}$ tabolism Disorder of Bone and Mineral in Chronic Kidney Disease (Japanese Society for Dialysis Therapy) [18]. The intact PTH target level was $60-240 \mathrm{pg} / \mathrm{mL}$.

Calcium carbonate and other hyperphosphatemia medication (lanthanum carbonate, sevelamer, or bixalomer) were discontinued before starting the trial. The use of calcium carbonate and sevelamer for the bixalomer group was prohibited, as was the use of bixalomer and sevelamer in the calcium carbonate group. The use of lanthanum carbonate was permitted, as described above when it was impossible to maintain serum phosphorus levels within the target range. The use of activated vitamin $\mathrm{D}$ was permitted when the serum calcium level was low, with the dose of vitamin D adjusted as necessary. The use of cinacalcet was permitted when the intact PTH level was high, with the dose of cinacalcet adjusted as necessary. The concentration of calcium in the dialysis solution remained unchanged during the observation period.

\section{Outcomes}

The primary endpoint was the change in coronary artery calcium (CAC) score from baseline to 12 months of treatment measured by multi-slice CT scan (SIEMENS, Berlin, Germany; GE, MA, USA; Toshiba Medical Systems Corp., Tochigi Prefecture, Japan). Patients were simultaneously treated and observed for 12 months. Patients who did not complete the 12-month treatment/ observation period were considered as discontinued from the study.

Secondary endpoints were changes in serum phosphorus and calcium levels during the study. Other secondary endpoints included changes in intact PTH, serum fibroblast growth factor (FGF)-23, serum $\alpha$-klotho, serum pentosidine, high-sensitivity C-reactive protein (Hs-CRP), low-density lipoprotein cholesterol (LDL-C), N-terminal prohormone of brain natriuretic peptide (NT-proBNP), and cardiovascular event-free survival rate. Adverse events (AEs) were evaluated for safety.

To assess the primary endpoint (change in CAC score from baseline to the last visit), CT assessments were done at baseline, 6 months, and 12 months. Weighted density scores were assigned to the highest attenuation value multiplied by the area of the calcification speck. The density factors were 130-199 Hounsefield units (HU), 1; 200-299 HU, 2; 300-399 HU, 3; and $\geq 400 \mathrm{HU}$ 4. All areas of calcification with a minimal density of 130 $\mathrm{HU}$ within the borders of the coronary arteries (main trunk, left anterior descending artery, right coronary artery, and circumflex artery) were computed. Patients with evaluable calcification in all four sites were included in the analysis. At least three contiguous pixels with a density of $\geq 130 \mathrm{HU}$ were required for the confirmed presence of a calcified plaque (an area equivalent to 1.03 $\mathrm{mm}^{2}$ ). Zio software (Ziosoft Inc., Tokyo, Japan) was used to calculate the scores by counting the pixels in imaging scans. The scores of all calcified specks were summed to calculate the total CAC score [19]. Scans free of artifacts were considered to be of acceptable quality. For consistency of interpretation, a single investigator who was unaware of the clinical status and treatment of the patient reviewed the scans.

To evaluate secondary endpoints, blood samples were analyzed at a central laboratory (FGF23, Hs-CRP, and $\alpha$-klotho were analyzed by SLR, Inc., Tokyo, and other parameters were analyzed by each hospital's standard laboratory company) using standardized assays. Serum phosphorus, calcium, and albumin levels were measured at baseline and every month; intact PTH levels were measured at baseline and every 3 months; FGF23, 
$\alpha$-klotho, pentosidine, and Hs-CRP levels were measured at baseline and every 6 months; and all other laboratory parameters, including NT-proBNP, were measured at baseline and every 6 months.

\section{Sample size}

Based on previous studies [10, 12], a target sample size was calculated using the data obtained by a two-group $t$ test with a two-sided alpha error rate of $5 \%$ and a common standard deviation of $20 \mathrm{mg}^{2} / \mathrm{dL}^{2}$. We estimated that 300 patients would provide $90 \%$ power of detecting any possible significant difference.

\section{Randomization and blinding}

Randomization was done via a central registry using the permuted-block method. Electronic data capture (EDC) (CliSSS EDC Ver.1.0, Forte Research Systems) was used for the computer-generated randomization schedule. Only the investigator who assessed the CT scans for the primary endpoint (change in CAC score) was blinded.

\section{Statistical methods}

Continuous variables are presented as mean \pm standard deviation (SD) and frequency variables as the number of cases and percentages. Comparisons between groups were conducted using the parametric method (i.e., unpaired $t$ test) if a normal distribution was confirmed. Changes from baseline over time were compared using the paired $t$ test if a normal distribution was confirmed. Between-group comparisons in frequency variables were performed using Fisher's exact test or the chi-square test. The Wilcoxon rank sum test for continuous variables was used if a normal distribution was not confirmed. Measured values of discontinued and withdrawn cases were included in the analysis up until discontinuation/ withdrawal if they had been collected after starting the trial. Missing values were not imputed. All probability values were two-tailed. $P$ values $<0.05$ were considered statistically significant. All analyses were conducted using SAS 9.3 (Cary, NC, USA). Statistical analyses of the present study were performed by Meditrix Corporation, Tokyo, Japan.

\section{Results}

A total of 85 patients were randomized to the bixalomer $(n=44)$ and calcium carbonate $(n=41)$ groups. One patient in each group discontinued from the study before treatment. Thus, $83(97.6 \%)$ patients received treatment and were included in the efficacy and safety analysis sets: 43 and 40 patients in the bixalomer and calcium carbonate groups, respectively (Fig. 1).

\section{Patient characteristics}

The mean age of patients was 66.0 and 66.1 years in the bixalomer and calcium carbonate groups, respectively.
Predominantly, male patients were enrolled in the two groups $-69.8 \%$ and $82.5 \%$, respectively (Table 1 ).

Proportions of patients with diabetes were $37.2 \%$ and $32.5 \%$ in the bixalomer and calcium carbonate groups, respectively. At baseline, 28 patients were receiving concomitant treatment with lanthanum carbonate $34.9 \%$ of patients in the bixalomer group and $32.5 \%$ of patients in the calcium carbonate group) (Table 1). Among 83 patients, $40(48.2 \%)$ initiated or restarted lanthanum carbonate treatment during the study $(48.8 \%$ [21/43] in the bixalomer group and $47.5 \%$ [19/40] in the calcium carbonate group) (Table 2).

At baseline, the mean $( \pm \mathrm{SD}) \mathrm{CAC}$ scores in the bixalomer and calcium carbonate groups were $947.2 \pm 1013.5$ vs $1210.1 \pm 1962.8(p=0.451)$. In the two groups, the values for serum phosphorus, calcium, and intact PTH were 5.32 vs $5.32 \mathrm{mg} / \mathrm{dL}, 9.15$ vs $9.05 \mathrm{mg} / \mathrm{dL}$, and 173.0 vs $134.4 \mathrm{pg} / \mathrm{mL}$, respectively.

In the bixalomer group, the last visit (end of treatment) occurred at 6 months in seven patients and at 12 months in 31 patients. In the calcium carbonate group, the last visit occurred at 6 months in one patient and at 12 months in 34 patients.

\section{Efficacy \\ CAC scores}

At 6 months, the mean $( \pm \mathrm{SD})$ CAC score was lower in the bixalomer group vs the calcium carbonate group $(1052.4 \pm 1091.1$ vs $1367.6 \pm 2131.5$, respectively). Similarly, at 12 months, the mean $( \pm$ SD) CAC score was lower in the bixalomer group vs the calcium carbonate group (987.3 \pm 1042.9 vs $1528.0 \pm 2313.1$, respectively) (Table 3). However, there was no significant difference between the two treatment groups in the mean $( \pm$ SD) CAC scores at 6 months $(-315.2$ [95\% CI -1096.3 , $465.9 ; p=0.424])$ and 12 months $(-540.7 \quad[95 \% \mathrm{Cl}$ $-1445.0,363.6 ; p=0.237])$.

The mean $( \pm \mathrm{SD})$ changes in the CAC scores from baseline to 6 months $(125.4 \pm 157.2[p<0.001]$ vs $81.3 \pm 136.8$ $[p=0.001]$, respectively) and to 12 months $(268.6 \pm 320.1$ $[p<0.001]$ vs $126.7 \pm 154.8[p<0.001])$ were significantly higher in the calcium carbonate group vs the bixalomer group. However, a significant mean difference between groups was only observed at 12 months of treatment $(-141.9$ [95\% CI $-268.5,-15.3 ; p=0.029])$ (Table 4).

\section{Serum phosphorus, calcium, and intact PTH}

Mean ( \pm SD) serum phosphorus levels at 3, 6, and 12 months were $5.87 \pm 1.15,5.73 \pm 1.29$, and $5.65 \pm 1.14 \mathrm{mg} /$ $\mathrm{dL}$, respectively, in the bixalomer group, and $4.95 \pm 1.33$, $5.13 \pm 1.06$, and $4.93 \pm 1.18 \mathrm{mg} / \mathrm{dL}$ in the calcium carbonate group. The difference between the two groups at 3,6 , and 12 months was $0.93 \mathrm{mg} / \mathrm{dL}$ (95\% CI $0.36,1.50$ $\mathrm{mg} / \mathrm{dL} ; p=0.002), 0.61 \mathrm{mg} / \mathrm{dL}(95 \%$ CI $0.06,1.16 \mathrm{mg} / \mathrm{dL}$; 


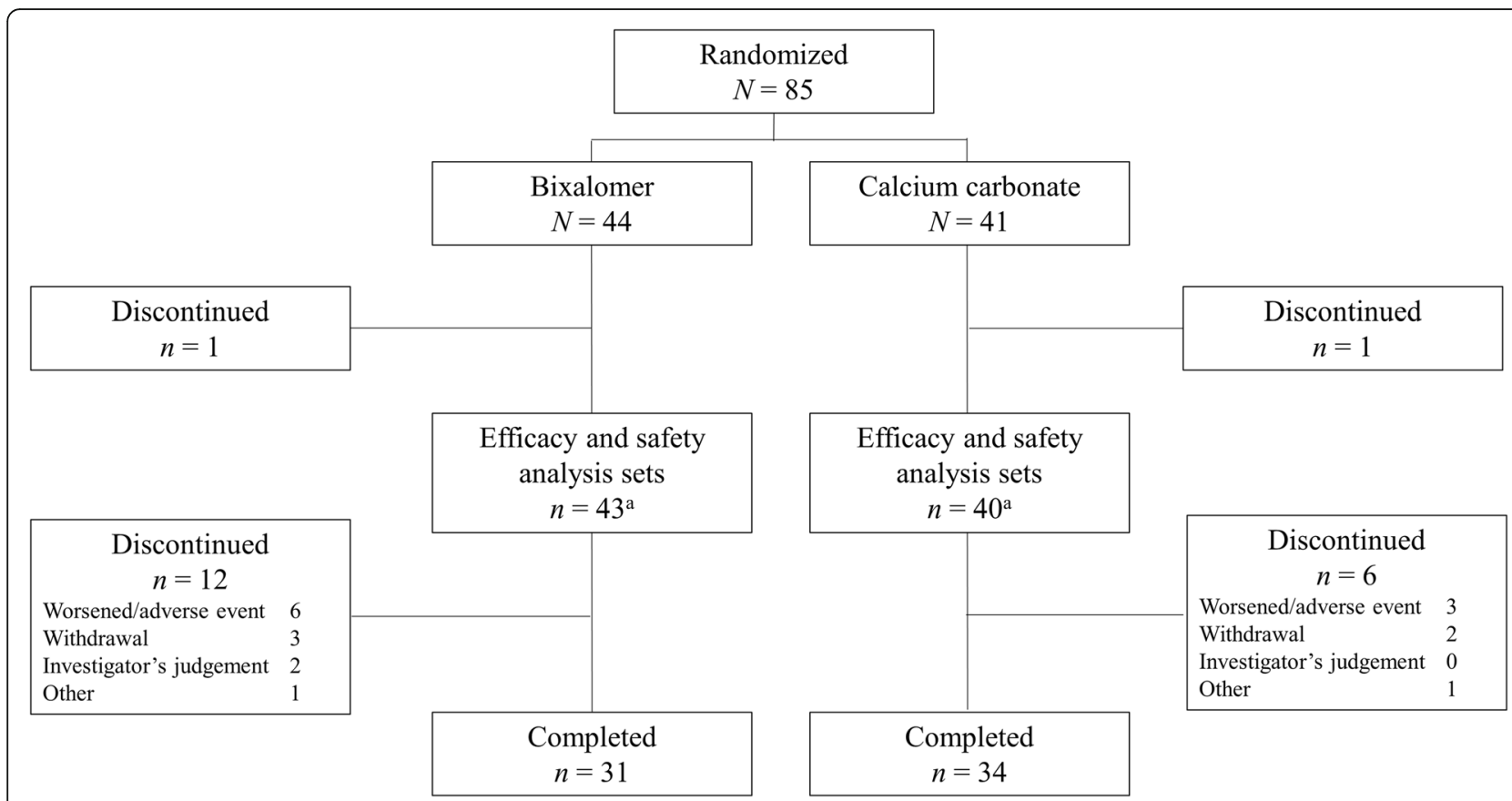

Fig. 1 Patient disposition. ${ }^{\text {TT }}$ The number of patients who initiated or restarted lanthanum carbonate treatment was 21 in the bixalomer group and 19 in the calcium carbonate group. In the bixalomer group, the "Other" reason for discontinuation in one patient was that the patient felt nausea. In the calcium carbonate group, the "Other" reason for discontinuation in one patient was that the patient was transferred for psychiatric reasons

$p=0.030)$, and $0.71 \mathrm{mg} / \mathrm{dL}(95 \% \mathrm{CI} 0.14,1.29 \mathrm{mg} / \mathrm{dL} ; p$ $=0.015)$, respectively (Table 5 ).

Table 5 shows the serum calcium levels in the two groups at 3, 6, and 12 months. There were significant differences between the two groups at $6(p=0.040)$ and 12 months $(p=0.004)$, but not at 3 months $(p=0.065)$.

There was no significant difference in intact $\mathrm{PTH}$ levels between the two groups at baseline $(p=0.073)$. However, there was increasing divergence between the two groups at 3, 6, and 12 months, and a statistically significant difference in intact PTH levels between the groups was reached at 12 months $(192.2 \pm 95.0 \mathrm{pg} / \mathrm{mL}$ in the bixalomer group and $141.4 \pm 91.4 \mathrm{pg} / \mathrm{mL}$ in the calcium carbonate group; $p=0.032$ ) (Table 5).

\section{Other parameters}

There were no significant differences between the two groups for other laboratory parameters assessed, including FGF23, $\alpha$-klotho, pentosidine, Hs-CRP, LDL-C, and NT-proBNP (Additional file 1).

We did not conduct any analysis of the cardiovascular event-free survival rate because there was only one cardiovascular event in the bixalomer group. This patient had a revascularization at 273 days of initiating bixalomer treatment.

\section{Safety}

Table 6 shows the AEs in the two groups. The most common AEs were shunt stenosis in the bixalomer group and shunt stenosis and common cold in the calcium carbonate group. There was no significant difference in the incidence of AEs between the two groups. No serious AEs or deaths were reported in any group during the study duration.

\section{Discussion}

This is the first study to compare the effect of bixalomer with that of calcium carbonate on coronary artery calcification in hemodialysis patients with hyperphosphatemia. In this study, the target of 300 patients was not achieved, and only 85 patients were randomized. The enrollment period of this study coincided with the enrollment period of other large clinical trials of new CKD-MBD-related drugs; thus, it was difficult to recruit patients for this study. However, the sample of 85 patients was adequate for statistical comparisons.

When compared with calcium-based binders, calcium-free treatment options are preferred and are increasingly being evaluated for the treatment of hyperphosphatemia in patients on hemodialysis [20]. In the current study, significant mean changes in the CAC scores were reported with bixalomer at 12 months when compared with calcium carbonate (126.7 \pm 154.8 vs $268.6 \pm 320.1 ; p=0.029)$. Patients treated with bixalomer also attained significant changes in serum calcium $(p=$ $0.004)$, phosphorus $(p=0.015)$, and intact PTH levels $(p$ $=0.032$ ) at 12 months. 
Table 1 Baseline characteristics of patients

\begin{tabular}{|c|c|c|c|}
\hline & Total, $N=83$ & Bixalomer, $n=43$ & Calcium carbonate, $n=40$ \\
\hline Concomitant treatment with lanthanum carbonate & $28(33.7)$ & $15(34.9)$ & $13(32.5)$ \\
\hline Male sex & $63(75.9)$ & $30(69.8)$ & $33(82.5)$ \\
\hline Age (years), mean $\pm S D$ & $66.0 \pm 9.8$ & $66.0 \pm 9.6$ & $66.1 \pm 10.1$ \\
\hline Height $(\mathrm{cm})$, mean \pm SD & $160.9 \pm 7.1$ & $159.9 \pm 7.1$ & $162.0 \pm 7.2$ \\
\hline Weight $(\mathrm{kg})$, mean $\pm \mathrm{SD}$ & $57.3 \pm 9.6$ & $56.1 \pm 9.1$ & $58.5 \pm 10.0$ \\
\hline \multicolumn{4}{|l|}{ Underlying disease } \\
\hline Diabetic nephropathy & $28(33.7)$ & $15(34.9)$ & $13(32.5)$ \\
\hline Chronic glomerulonephritis & $16(19.3)$ & $8(18.6)$ & $8(20.0)$ \\
\hline Nephrosclerosis & $17(20.5)$ & $11(25.6)$ & $6(15.0)$ \\
\hline Cystic kidney & $4(4.8)$ & $0(0.0)$ & $4(10.0)$ \\
\hline Chronic pyelonephritis & $2(2.4)$ & $2(4.7)$ & $0(0.0)$ \\
\hline Other & $16(19.3)$ & $7(16.3)$ & $9(22.5)$ \\
\hline \multicolumn{4}{|l|}{ History of dialysis (years) } \\
\hline$<1$ & $8(9.8)$ & $3(7.0)$ & $5(12.8)$ \\
\hline$\geq 1,<5$ & 29 (35.4) & $13(30.2)$ & $16(41.0)$ \\
\hline$\geq 5,<10$ & $21(25.6)$ & $14(32.6)$ & $7(17.9)^{\mathrm{a}}$ \\
\hline$\geq 10,<15$ & $14(17.1)$ & $9(20.9)$ & $5(12.8)$ \\
\hline$\geq 15$ & $10(12.2)$ & $4(9.3)$ & $6(15.4)$ \\
\hline \multicolumn{4}{|l|}{ Method of dialysis } \\
\hline Hemodialysis & $69(83.1)$ & $35(81.4)$ & $34(85.0)$ \\
\hline Hemodiafiltration & $14(16.9)$ & $8(18.6)$ & $6(15.0)$ \\
\hline \multicolumn{4}{|l|}{ Dialysate calcium concentration (mEq/L) } \\
\hline 2.5 & $4(4.8)$ & $2(4.7)$ & $2(5.0)$ \\
\hline 2.75 & $11(13.3)$ & $4(9.3)$ & $7(17.5)$ \\
\hline 3.0 & $68(81.9)$ & $37(86.0)$ & $31(77.5)$ \\
\hline Other & $0(0.0)$ & $0(0.0)$ & $0(0.0)$ \\
\hline Complication & $81(97.6)$ & $42(97.7)$ & $39(97.5)$ \\
\hline High blood pressure & $65(78.3)$ & $36(83.7)$ & $29(72.5)$ \\
\hline Diabetes & $29(34.9)$ & $16(37.2)$ & $13(32.5)$ \\
\hline Anemia in $C K D^{b}$ & $57(68.7)$ & $32(74.4)$ & $25(62.5)$ \\
\hline Secondary hyperparathyroidism & $33(39.8)$ & $16(37.2)$ & $17(42.5)$ \\
\hline Constipation & $30(36.1)$ & $19(44.2)$ & $11(27.5)$ \\
\hline Itchy skin & $15(18.1)$ & $8(18.6)$ & $7(17.5)$ \\
\hline Other & $51(61.4)$ & $28(65.1)$ & $23(57.5)$ \\
\hline Combination drug & $73(88.0)$ & $39(90.7)$ & $34(85.0)$ \\
\hline Antihypertensive & $65(78.3)$ & $38(88.4)$ & $27(67.5)$ \\
\hline Drug for osteoporosis & 33 (39.8) & $20(46.5)$ & $13(32.5)$ \\
\hline Drug for dyslipidemia & $21(25.3)$ & $11(25.6)$ & $10(25.0)$ \\
\hline No combination therapy ${ }^{c}$ & $80(96.4)$ & $41(95.3)$ & $39(97.5)$ \\
\hline
\end{tabular}

Data are presented as $n(\%)$ unless otherwise stated

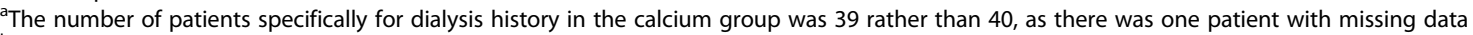

${ }^{b}$ Anemia in CKD is defined as hemoglobin level $<11.0 \mathrm{~g} / \mathrm{dL}$ or erythropoietin use in patients with CKD

'Patients not receiving any therapy other than that for hemodialysis or hemodiafiltration

Abbreviations: $C K D$ chronic kidney disease, $S D$ standard deviation 
Table 2 Concomitant treatment with lanthanum carbonate during the study

\begin{tabular}{|c|c|c|c|c|}
\hline Use of lanthanum carbonate at baseline & Use of lanthanum carbonate during the study & Total, $N=83$ & Bixalomer, $n=43$ & Calcium carbonate, $n=40$ \\
\hline \multirow[t]{5}{*}{$Y e s, N=28$} & No or lacking data, $n$ (\%) & $8(28.6)$ & $6(40.0)$ & $2(15.4)$ \\
\hline & Yes, $n(\%)$ & $20(71.4)$ & $9(60.0)$ & $11(84.6)$ \\
\hline & Mean \pm SD & $1023 \pm 647$ & $1153 \pm 796$ & $917 \pm 511$ \\
\hline & Median & 750 & 750 & 750 \\
\hline & Minimum/maximum & $350 / 2250$ & $429 / 2250$ & $350 / 1875$ \\
\hline \multirow[t]{5}{*}{ No, $N=55$} & No or lacking data, $n(\%)$ & $35(63.6)$ & $16(57.1)$ & $19(70.4)$ \\
\hline & Yes, $n(\%)$ & $20(36.4)$ & $12(42.9)$ & $8(29.6)$ \\
\hline & Mean \pm SD & $864 \pm 522$ & $831 \pm 637$ & $914 \pm 311$ \\
\hline & Median & 750 & 750 & 781 \\
\hline & Minimum/maximum & $250 / 2250$ & $250 / 2250$ & $500 / 1375$ \\
\hline
\end{tabular}

Abbreviation: $S D$ standard deviation

Similar findings have been reported in other trials evaluating calcium-free options in hemodialysis patients $[10,21]$. Sevelamer, a non-absorbed, non-calcium-containing polymer has been compared with calcium-based binders in a randomized trial [10] and was shown to be less likely to cause hypercalcemia ( $16 \%$ vs $5 \%$ with sevelamer, $p=0.04$ ) and low levels of intact PTH $(57 \%$ vs $30 \%, p=0.001)$ in hemodialysis patients $(n=200)$. Progressive coronary and aortic calcification was reported in patients receiving calcium-based binders. There was a significant increase in the median absolute calcium score in the coronary arteries and aortas of patients who received calcium-based binders but not in those treated with sevelamer (coronary arteries 36.6 vs 0 , $p=0.03$; aorta 75.1 vs $0, p=0.01$, respectively) [10].

The use of calcium-containing phosphate binders causes more rapid progression of coronary calcification in patients who are new to dialysis. In a randomized trial, 129 new dialysis patients received calcium-containing phosphate binders or sevelamer hydrochloride and were followed up with CT assessments at 6,12 , and 18 months. When compared with those receiving sevelamer hydrochloride, patients treated with calcium-containing phosphate binders showed more rapid and more severe increases in CAC scores both at $12(p=0.056)$ and 18 months $(p$ $=0.01$ ) [11]. These results were comparable to findings in the current study. The higher level of calcification observed with calcium carbonate in the present study may be attributed to the higher level of corrected $\mathrm{Ca}$ value in the calcium carbonate group compared with that in the bixalomer group.

A strength of this study is the inclusion of patients who have been on long-term dialysis, i.e., $\geq 15$ years. Available studies comparing calcium-based binders

Table 3 CAC scores at baseline, 6 months, and 12 months (during the 12-month observation period)

\begin{tabular}{llll}
\hline CAC scores & Baseline & 6 months & 12 months \\
\hline Bixalomer, $N$ & 41 & 38 & 31 \\
Mean \pm SD & $947.2 \pm 1013.5$ & $1052.4 \pm 1091.1$ & $987.3 \pm 1042.9$ \\
$95 \%$ Cl & $627.3,1267.1$ & $693.8,1411.1$ & $604.8,1369.9$ \\
Median & 493.55 & 642.41 & 583.82 \\
Minimum/maximum & $0 / 3484.5$ & $0 / 3541.2$ & $0 / 3830.9$ \\
Calcium carbonate, $N$ & 39 & 35 & 34 \\
Mean \pm SD & $1210.1 \pm 1962.8$ & $1367.6 \pm 2131.5$ & $1528.0 \pm 2313.1$ \\
$95 \%$ Cl & $573.8,1846.4$ & $635.5,2099.8$ & $720.9,2335.1$ \\
Median & 693.75 & 819.9 & 957.31 \\
Minimum/maximum & $0 / 11727.9$ & $0 / 12179.3$ & $0 / 13070.1$ \\
Difference between groups & -262.9 & -315.2 & -540.7 \\
$95 \%$ Cl & $-953.3,427.5$ & $-1096.3,465.9$ & $-1445.0,363.6$ \\
$P$ value & 0.451 & 0.424 & 0.237 \\
\hline
\end{tabular}

${ }^{a}$ Comparisons between groups were conducted using the $t$ test

Abbreviations: $C A C$ coronary artery calcium, $C$ confidence interval, $N$ number of patients, $S D$ standard deviation 
Table 4 Changes in CAC score from baseline to 6 and 12 months (primary endpoint)

\begin{tabular}{|c|c|c|c|c|}
\hline & Change in CAC scores at 6 months & $P$ value & Change in CAC scores at 12 months & $P$ value \\
\hline Bixalomer, $N$ & 38 & & 31 & \\
\hline Mean \pm SD & $81.3 \pm 136.8$ & 0.001 & $126.7 \pm 154.8$ & $<0.001$ \\
\hline $95 \% \mathrm{Cl}$ & $36.3,126.3$ & & $69.9,183.5$ & \\
\hline Median & 49.53 & & 113.53 & \\
\hline Minimum/maximum & $-144.39 / 592.2$ & & $-92.79 / 653.2$ & \\
\hline Calcium carbonate, $N$ & 35 & & 34 & \\
\hline Mean \pm SD & $125.4 \pm 157.2$ & $<0.001$ & $268.6 \pm 320.1$ & $<0.001$ \\
\hline $95 \% \mathrm{Cl}$ & $71.4,179.4$ & & $157.0,380.3$ & \\
\hline Median & 59.62 & & 176.92 & \\
\hline Minimum/maximum & $-62.69 / 621.7$ & & $-24.69 / 1342.2$ & \\
\hline Difference between groups & -44.1 & & -141.9 & \\
\hline $95 \% \mathrm{Cl}$ & $-112.8,24.5$ & & $-268.5,-15.3$ & \\
\hline$P$ value ${ }^{a}$ & 0.204 & & 0.029 & \\
\hline
\end{tabular}

${ }^{a}$ Changes from baseline over time were compared between groups using the paired $t$ test

Abbreviations: $C A C$ coronary artery calcium, $C$ confidence interval, $N$ number of patients, $S D$ standard deviation

and calcium-free polymers have usually been conducted in patients on dialysis for 2-3 years or those new (within 120 days) to dialysis $[10,11]$. Further, patients enrolled in the current study were older (mean age, 66 years) than those in previous studies (mean age, 50-60 years) comparing calcium-based and calcium-free treatment options $[10,11]$. Another strength of this study was that it was conducted in usual patient settings and provides real-life experience of bixalomer in hemodialysis patients.

The safety of bixalomer was comparable to that of calcium carbonate. The most common AEs were shunt stenosis in the bixalomer group and both shunt stenosis and common cold in the calcium carbonate group. When compared with sevelamer, bixalomer has better tolerability $[14,15]$.

Bixalomer attenuates the risk of progressive coronary artery calcification in patients undergoing hemodialysis. Additionally, these data suggest that introduction of bixalomer therapy may be beneficial in end-stage renal disease irrespective of the duration of hemodialysis before initiation of therapy.

\section{Limitations}

This study is the first report to show lower calcification action with bixalomer compared with calcium carbonate. However, there are some limitations.

The CAC score has been used for risk stratification and treatment monitoring in patients undergoing hemodialysis $[10,11]$. Although it is not clear whether CAC scores are indicative of atherosclerosis or elastocalcinosis, they are widely used because of their non-invasiveness and repeatability [22].
Age, C-reactive protein, and pulse wave velocity have previously been reported as factors associated with coronary artery calcification in end-stage renal disease [23], but the current study did not evaluate the contributors to coronary artery calcification. We considered the reduction of calcium and intact PTH concentrations; however, phosphorus, calcium, and intact PTH concentrations were towards the higher limits. These parameters can potentially promote heterotopic calcification in the bixalomer group, so it is difficult to determine whether these factors contributed to CAC progression in the calcium carbonate group.

The 1-year follow-up of patients in the current study yielded adequate comparisons for bixalomer and calcium carbonate. However, studies evaluating the effects of bixalomer over extended periods should be conducted to assess the long-term effect on CAC scores. Previous studies evaluating CAC scores in hemodialysis patients have followed-up patients with annual assessments for $\geq 2$ years [21].

No significant changes in laboratory parameters such as FGF23, $\alpha$-klotho, pentosidine, Hs-CRP, LDL-C, and NT-proBNP were found in the current study due to the small number of patients. Future studies should include these assessments for evaluating bixalomer in patients with hemodialysis.

The mechanism of attenuation of the progression of coronary and aortic calcification of bixalomer is poorly understood. Like sevelamer, bixalomer can be assumed to lower the oral calcium load. However, other possible mechanisms such as reduction of hypercalcemia, change of PTH control, or improvement in hyperlipidemia should be further evaluated. 
Table 5 Phosphate, calcium, and intact PTH levels throughout the study period

\begin{tabular}{|c|c|c|c|c|}
\hline & Baseline & 3 months & 6 months & 12 months \\
\hline \multicolumn{5}{|l|}{ Phosphate, mg/dL } \\
\hline Bixalomer, $N$ & 43 & 38 & 38 & 31 \\
\hline Mean \pm SD & $5.32 \pm 1.23$ & $5.87 \pm 1.15$ & $5.73 \pm 1.29$ & $5.65 \pm 1.14$ \\
\hline $95 \% \mathrm{Cl}$ & $4.94,5.70$ & $5.50,6.25$ & $5.31,6.16$ & $5.23,6.06$ \\
\hline Median & 5.3 & 5.8 & 5.8 & 5.7 \\
\hline Minimum/maximum & $2.8 / 8.0$ & $3.7 / 8.7$ & $2.5 / 8.9$ & $3.7 / 8.3$ \\
\hline Calcium carbonate, $N$ & 40 & 38 & 36 & 35 \\
\hline Mean \pm SD & $5.32 \pm 1.10$ & $4.95 \pm 1.33$ & $5.13 \pm 1.06$ & $4.93 \pm 1.18$ \\
\hline $95 \% \mathrm{Cl}$ & $4.96,5.67$ & $4.51,5.39$ & $4.77,5.48$ & $4.53,5.34$ \\
\hline Median & 5.2 & 5.1 & 5.1 & 5.0 \\
\hline Minimum/maximum & $3.3 / 7.8$ & $2.1 / 8.1$ & $2.4 / 7.2$ & $2.8 / 7.6$ \\
\hline Difference between groups, Mean & 0.01 & 0.93 & 0.61 & 0.71 \\
\hline $95 \% \mathrm{Cl}$ & $-0.51,0.52$ & $0.36,1.50$ & $0.06,1.16$ & $0.14,1.29$ \\
\hline$P$ value ${ }^{a}$ & 0.982 & 0.002 & 0.030 & 0.015 \\
\hline \multicolumn{5}{|l|}{ Calcium, mg/dL } \\
\hline Bixalomer, $N$ & 43 & 38 & 38 & 31 \\
\hline Mean \pm SD & $9.15 \pm 0.70$ & $8.89 \pm 0.49$ & $8.91 \pm 0.62$ & $8.85 \pm 0.56$ \\
\hline $95 \% \mathrm{Cl}$ & $8.94,9.37$ & $8.73,9.05$ & $8.70,9.11$ & $8.64,9.05$ \\
\hline Median & 9.1 & 9.0 & 8.9 & 8.9 \\
\hline Minimum/maximum & $8.3 / 11.8$ & $7.8 / 10.1$ & $7.5 / 10.1$ & $7.6 / 9.7$ \\
\hline Calcium carbonate, $N$ & 40 & 38 & 36 & 35 \\
\hline Mean \pm SD & $9.05 \pm 0.75$ & $9.16 \pm 0.72$ & $9.23 \pm 0.72$ & $9.33 \pm 0.75$ \\
\hline $95 \% \mathrm{Cl}$ & $8.81,9.28$ & $8.92,9.39$ & $8.99,9.48$ & $9.07,9.59$ \\
\hline Median & 9.0 & 9.1 & 9.1 & 9.4 \\
\hline Minimum/maximum & $7.0 / 11.2$ & $7.8 / 10.9$ & $8.0 / 11.5$ & 7.9/10.6 \\
\hline Difference between groups, Mean & 0.11 & -0.26 & -0.33 & -0.49 \\
\hline $95 \% \mathrm{Cl}$ & $-0.21,0.42$ & $-0.54,0.02$ & $-0.64,-0.02$ & $-0.82,-0.16$ \\
\hline$P$ value $^{a}$ & 0.505 & 0.065 & 0.040 & 0.004 \\
\hline \multicolumn{5}{|l|}{ Intact PTH, pg/mL } \\
\hline Bixalomer, $N$ & 40 & 35 & 36 & 31 \\
\hline Mean \pm SD & $173.0 \pm 102.6$ & $200.1 \pm 98.2$ & $208.4 \pm 96.7$ & $192.2 \pm 95.0$ \\
\hline $95 \% \mathrm{Cl}$ & $140.2,205.9$ & $166.4,233.8$ & $175.7,241.2$ & $157.4,227.1$ \\
\hline Median & 149 & 208 & 184.5 & 180 \\
\hline Minimum/maximum & $11 / 395$ & $7 / 423$ & $47 / 382$ & 9/393 \\
\hline Calcium carbonate, $N$ & 38 & 35 & 32 & 34 \\
\hline Mean \pm SD & $134.4 \pm 83.7$ & $120.9 \pm 84.9$ & $163.1 \pm 107.8$ & $141.4 \pm 91.4$ \\
\hline $95 \% \mathrm{Cl}$ & $106.9,161.9$ & $91.7,150.0$ & $124.2,201.9$ & $109.4,173.3$ \\
\hline Median & 127.5 & 121 & 158 & 125.5 \\
\hline Minimum/maximum & $5 / 376$ & $2 / 311$ & $8 / 460$ & $9 / 358$ \\
\hline Difference between groups, Mean & 38.6 & 79.2 & 45.4 & 50.9 \\
\hline $95 \% \mathrm{Cl}$ & $-3.7,81.0$ & $35.5,123.0$ & $-4.1,94.9$ & $4.7,97.1$ \\
\hline$P$ value $^{a}$ & 0.073 & 0.001 & 0.072 & 0.032 \\
\hline
\end{tabular}

${ }^{\mathrm{a} C o m p a r i s o n s ~ b e t w e e n ~ g r o u p s ~ w e r e ~ c o n d u c t e d ~ u s i n g ~} t$ test

Abbreviations: $\mathrm{Cl}$ confidence interval, $\mathrm{N}$ number of patients, $P T H$ parathyroid hormone, SD standard deviation 
Table 6 Adverse events for which more than two events were reported

\begin{tabular}{llll}
\hline & Bixalomer, $N=43$ & Calcium carbonate, $N=40$ & $P$ value \\
\hline Shunt stenosis & 7 events/5 patients & 10 events/4 patients & 1.0000 \\
Common cold & - & 7 events/6 patients & 0.0102 \\
Pyrexia & 2 events/1 patient & - & 1.0000 \\
Constipation & 2 events/2 patients & - & 0.4946 \\
Cystitis & - & 2 events/1 patient & 0.4819 \\
\hline
\end{tabular}

${ }^{\mathrm{a}}$ Fisher's exact test

\section{Conclusions}

When compared with calcium carbonate, bixalomer reduced the progression of $\mathrm{CAC}$ in patients undergoing hemodialysis. This is due to the decreased oral calcium load with bixalomer. Further investigations in well-designed trials can help to determine whether bixalomer is associated with a decreased risk of cardiovascular death in hemodialysis patients.

\section{Additional file}

Additional file 1: Results of other laboratory parameters. (DOCX $27 \mathrm{~kb}$ )

\section{Abbreviations}

AE: Adverse events; CAC: Coronary artery calcium; Cl: Confidence interval; CKD: Chronic kidney disease; CT: Computed tomography; EDC: Electronic data capture; FGF: Fibroblast growth factor; Hs-CRP: C-reactive protein; HU: Hounsefield units; KDIGO: Kidney Disease: Improving Global Outcomes; LDL-C: Low-density lipoprotein cholesterol; MBD: Mineral and bone disorder; NT-proBNP: N-terminal prohormone of brain natriuretic peptide; PTH: Parathyroid hormone; SD: Standard deviation

\section{Acknowledgements}

The authors wish to thank Astellas Pharma Inc. for financial support. The authors also thank Yoshinari Tsuruta from Meiyo Clinic, Yoshiko Tanaka from Shinjuku Ishikawa Clinic, Hajime Miyata from Matsui Hospital, Yuki Shindo from Nagahara Sanwa Clinic, Hajime Ogawa from Ogawa Clinic, Rio Kimura from Shimokitazawa Ekimae Clinic, Tomokatsu Saijo from Saijyo Clinic Takaban, Masanori Ikeda from Oi Ogawa Clinic, Masayuki Takayama from Medical Corporation Seisuikai Takayama Clinic, Toshiaki Suzuki from Asagaya Suzuki Clinic, Makoto Watanabe from Makita General Hospital, Hitoshi Tagawa from Medical Corporation Toujinkai Kichijoji Asahi Hospital, Fumio Yoneda from Kichijoji Ekimae Clinic, Kenji Kikuchi from Medical Corporation Toujinkai Mitakajin Clinic, Kan Kikuchi from Shimoochiai Clinic, Shigeru Otsubo from Sangenjaya Hospital, Shinya Suganuma from Kidney Clinic Setagaya, Yuji Ishida from Ishida Clinic, Yoshiro Himeno from Musashino Red Cross Hospital, Tatsuya Gomi from Toho University Ohashi Medical Center, and Yoshiyuki Takaishi from Narita Memorial Hospital. The authors thank the doctors, nurses, and clinical engineers who were engaged in the treatment of our patients. Finally, the authors also thank Siemens Healthcare Diagnostics K. K for providing clinical testing services, and Hikari Chiba, Helen Roberton, and Dr. Sarah Williams of Edanz Medical Writing for providing medical writing services.

\section{Funding}

This study was funded by Astellas Pharma Inc., which was not involved in the design of the study, in the collection, analysis and interpretation of data, or in writing the manuscript.

\section{Availability of data and materials}

The datasets generated and/or analyzed during the current study are not publicly available due to the confidentiality agreement contained within the informed consent from each patient. However, these datasets are available from the corresponding author upon reasonable request.

\section{Authors' contributions}

$T A, K Y, H H, M M, R A$, and TA developed the protocol. TA performed the interpretation of the data analysis. All authors participated in carrying out the study and data collection, and developed the manuscript. All authors read and approved the final manuscript.

\section{Ethics approval and consent to participate}

The study was carried out according to Ethical Guidelines for Medical and Health Research Involving Human Subjects published by the Ministry of Health, Labour and Welfare; the laws and regulatory requirements of Japan; and the ethical principles that have their origin in the Declaration of Helsinki (as revised in Tokyo 2004). The protocol, amendments, and subject informed consent forms were approved by the institutional review board/independent ethics committee at each site prior to study commencement.

\section{Consent for publication}

All patients, or their legally acceptable representatives, provided informed consent prior to entering the study.

\section{Competing interests}

Takashi Akiba reports receiving speaking fees from Bristol-Myers Squibb and manuscript writing fees from Torii Pharmaceutical. Keitaro Yokoyama reports receiving speaking fees from Torii Pharmaceutical, Ono Pharmaceutical, and Kissei Pharmaceutical. Tadao Akizawa reports receiving honoraria from Kyowa Hakko Kirin Pharma, Bayer Yakuhin, and Ono Pharmaceutical; speaking and personal fees from Kyowa Hakko Kirin Pharma, Bayer Yakuhin, Ono Pharmaceutical, Chugai Pharmaceutical, Kissei Pharmaceutical, and Torii Pharmaceutical; and manuscript writing fees from Astellas Pharma. Ryoichi Ando reports receiving speaking fees from Kyowa Hakko Kirin Pharma, Chugai Pharmaceutical, Torii Pharmaceutical, and Kissei Pharmaceutical. Shuji Sakai reports receiving scholarships from Eisai, Daiichi Sankyo, Fujifilm Corporation, Nihon Medi-Physics, and Fuji Pharma. Hiroki Hase reports receiving speaking fees from Chugai pharmaceutical and a scholarship from Kyowa Hakko Kirin Pharma. Masahide Mizobuchi and Kenji Fukushima report no conflicts of interest.

\section{Publisher's Note}

Springer Nature remains neutral with regard to jurisdictional claims in published maps and institutional affiliations.

\section{Author details}

${ }^{1}$ Tokyo Women's Medical University Hospital, Tokyo, Japan. ${ }^{2}$ Jikei University Hospital, Tokyo, Japan. ${ }^{3}$ Toho University Ohashi Medical Center, Tokyo, Japan. ${ }^{4}$ Department of Medicine, Division of Nephrology, Showa University School of Medicine, Tokyo, Japan. ${ }^{5}$ Musashino Red Cross Hospital, Tokyo, Japan. ${ }^{6}$ Present address: Tokyo Next Clinic, 2-22-1 Nishinippori Arakawaku, Tokyo 1160013, Japan.

Received: 13 September 2018 Accepted: 21 January 2019 Published online: 20 February 2019

\section{References}

1. Soohoo M, Feng M, Obi Y, Streja E, Rhee CM, Lau WL, et al. Changes in markers of mineral and bone disorders and mortality in incident hemodialysis patients. Am J Nephrol. 2016;43:85-96. 
2. Wang M, Obi Y, Streja E, Rhee CM, Lau WL, Chen J, et al. Association of parameters of mineral bone disorder with mortality in patients on hemodialysis according to level of residual kidney function. Clin J Am Soc Nephrol. 2017:12:1118-27.

3. Young EW, Albert JM, Satayathum S, Goodkin DA, Pisoni RL, Akiba T, et al. Predictors and consequences of altered mineral metabolism: the dialysis outcomes and practice patterns study. Kidney Int. 2005;67:1179-87.

4. Molony DA, Stephens BW. Derangements in phosphate metabolism in chronic kidney diseases/endstage renal disease: therapeutic considerations. Adv Chronic Kidney Dis. 2011;18:120-31.

5. KVOQI Clinical practice guidelines for bone metabolism and disease in children with chronic kidney disease. Am J Kidney Dis. 2005;46(4) Suppl 1):S2.

6. Improving Global Outcomes (KDIGO) CKD-MBD Work Group. KDIGO clinical practice guideline for the diagnosis, evaluation, prevention, and treatment of chronic kidney disease-mineral and bone disorder (CKD-MBD). Kidney Int Suppl. 2009;113:S1-S130.

7. Ketteler M, Block GA, Evenepoel P, Fukagawa M, Herzog CA, McCann L, et al. Executive summary of the 2017 KDIGO chronic kidney disease-mineral and bone disorder (CKD-MBD) guideline update: what's changed and why it matters. Kidney Int. 2017;92:26-36.

8. Goodman WG, Goldin J, Kuizon BD, Yoon C, Gales B, Sider D, et al. Coronary-artery calcification in young adults with end-stage renal disease who are undergoing dialysis. N Engl J Med. 2000;342:1478-83.

9. Peter WLS, Wazny LD, Weinhandl E, Cardone KE, Hudson JQ. A review of phosphate binders in chronic kidney disease: incremental progress or just higher costs? Drugs. 2017;77:1155-86.

10. Chertow GM, Burke SK, Raggi P. Sevelamer attenuates the progression of coronary and aortic calcification in hemodialysis patients. Kidney Int. 2002; 62:245-52.

11. Block GA, Spiegel DM, Ehrlich J, Mehta R, Lindbergh J, Dreisbach A, et al. Effects of sevelamer and calcium on coronary artery calcification in patients new to hemodialysis. Kidney Int. 2005;68:1815-24.

12. Kakuta T, Tanaka R, Hyodo T, Suzuki H, Kanai G, Nagaoka M, et al. Effect of sevelamer and calcium-based phosphate binders on coronary artery calcification and accumulation of circulating advanced glycation end products in hemodialysis patients. Am J Kidney Dis. 2011;57:422-31.

13. Guérin AP, London GM, Marchais SJ, Metivier F. Arterial stiffening and vascular calcifications in end-stage renal disease. Nephrol Dial Transplant. 2000;15:1014-21.

14. Akizawa T, Origasa H, Kameoka C, Kaneko Y, Kawasaki S. Randomized controlled trial of bixalomer versus sevelamer hydrochloride in hemodialysis patients with hyperphosphatemia. Ther Apher Dial. 2014;18:122-31.

15. Ito K, Takeshima A, Shishido K, Wakasa M, Kumata C, Matsuzaka K, et al. Treatment of hyperphosphatemia with bixalomer in Japanese patients on long-term hemodialysis with gastrointestinal symptoms. Ther Apher Dial. 2014;18(Suppl 2):19-23.

16. Furukawa K, Ikawa T, Yokoi S, Yokouchi S, Kato K, Ueno M, et al. Effects of switching from sevelamer hydrochloride to bixalomer on laboratory parameters in hemodialysis patients. Ther Apher Dial. 2014;18(Suppl 2):2-7. https://doi.org/10.1111/1744-9987.12227.

17. Shima H, Makino R, Hata K, Ban A, Funao K, Sugita S, et al. Clinical experiences of bixalomer usage at our hospital. Ther Apher Dial. 2014;18(Suppl 2):13-8.

18. Fukagawa M, Yokoyama K, Koiwa F, Taniguchi M, Shoji T, Kazama JJ, et al. Clinical practice guideline for the management of chronic kidney diseasemineral and bone disorder. Ther Apher Dial. 2013;17:247-88.

19. Agatston AS, Janowitz WR, Hildner FJ, Zusmer NR, Viamonte M Jr, Detrano R. Quantification of coronary artery calcium using ultrafast computed tomography. J Am Coll Cardiol. 1990;15:827-32.

20. Wang C, Liu X, Zhou Y, Li S, Chen Y, Wang Y, et al. New conclusions regarding comparison of sevelamer and calcium-based phosphate binders in coronary-artery calcification for dialysis patients: a meta-analysis of randomized controlled trials. PLoS One. 2015;10:e0133938.

21. Tsuruta Y, Ohbayashi T, Fujii M, Myochin H, Mizutani R, Narita M, et al. Change in coronary artery calcification score due to cinacalcet hydrochloride administration. Ther Apher Dial. 2008;12(Suppl 1):S34-7.

22. Nitta K, Akiba T, Suzuki K, Uchida K, Ogawa T, Majima K, et al. Assessment of coronary artery calcification in hemodialysis patients using multidetectorspiral CT scan. Hypertens Res. 2004;27:527-33.

23. Bashir A, Moody WE, Edwards NC, Ferro CJ, Townend JN, Steeds RP. Coronary artery calcium assessment in CKD: utility in cardiovascular disease risk assessment and treatment? Am J Kidney Dis. 2015;65:937-48.

\section{Ready to submit your research? Choose BMC and benefit from:}

- fast, convenient online submission

- thorough peer review by experienced researchers in your field

- rapid publication on acceptance

- support for research data, including large and complex data types

- gold Open Access which fosters wider collaboration and increased citations

- maximum visibility for your research: over $100 \mathrm{M}$ website views per year

At BMC, research is always in progress.

Learn more biomedcentral.com/submissions 